\title{
Promoção de Saúde, Desempenho Ocupacional e Vulnerabilidade Social: subsídios para a interven- ção da Terapia Ocupacional com adolescentes acolhidas institucionalmente
}

\section{Health Promotion, Occupational Performance and Social Vulnerability: subsidies for Occupational Therapy intervention with adolescents sheltered}

\author{
Daniel Gustavo de Sousa Carleto ${ }^{1}$, Heliana Castro Alves ${ }^{2}$, \\ Daniela Tavares Gontijo ${ }^{3}$
}

CARLETO, D. G. S.; AlveS, H. C.; GONTIJO, D. T. Promoção de Saúde, Desempenho Ocupacional e Vulnerabilidade Social: subsídios para a intervenção da Terapia Ocupacional com adolescentes acolhidas institucionalmente. Rev. Ter. Ocup. Univ. São Paulo, v. 21, n. 1, p. 89-97, jan./abr. 2010.

RESUMO: A Promoção de Saúde na perspectiva da Terapia Ocupacional se constrói a partir do envolvimento dos sujeitos em ocupações significativas. Circunstâncias em que as pessoas não possuem a oportunidade de se envolver nestas caracterizam a injustiça ocupacional, justificando adoção de estratégias de empoderamento que podem ser fundamentadas no Modelo de Empoderamento Ocupacional. Entre estas circunstâncias, destacam-se situações de vulnerabilidade social vivenciadas por adolescentes que foram acolhidas institucionalmente. Neste artigo, objetiva-se descrever e analisar o desempenho ocupacional destas, antes e durante o acolhimento institucional. Os dados foram coletados em uma instituição de abrigamento de crianças e adolescentes do sexo feminino através de entrevistas semi-estruturadas e observação participante, e analisados a partir de uma adaptação da técnica de Análise de Conteúdo. Duas categorias de análise foram elaboradas, nas quais são discutidas as atividades realizadas pelas adolescentes antes e durante o abrigamento, além da relação das redes sociais de suporte das adolescentes com desempenho ocupacional. De forma geral, percebeu-se a complexidade de fatores que caracterizam o desempenho ocupacional de adolescentes que vivenciam a vulnerabilidade social, sendo necessárias ações empoderadoras que envolvam intervenções direcionadas para as próprias adolescentes, assim como junto ao ambiente desempoderador, principalmente ações de fortalecimento da rede social de suporte.

DESCRITORES: Terapia ocupacional. Vulnerabilidade social. Adolescente. Promoção da saúde.

\footnotetext{
1. Acadêmico do Curso de Terapia Ocupacional na Universidade Federal do Triângulo Mineiro (UFTM).

2. Terapeuta Ocupacional, Docente do Curso de Terapia Ocupacional na UFTM. Pesquisadora do Núcleo de Estudos e Pesquisas em Vulnerabilidade e Saúde na Infância e Adolescência (NEPVIAS- UFTM).

${ }^{3}$. Terapeuta Ocupacional, Doutora em Ciências da Saúde. Docente do curso de Terapia Ocupacional da UFTM). Pesquisadora do NEPVIAS.

Endereço para correspondência: Av. Guilherme Ferreira, 350, Centro. Uberaba. E-mail : dgustavosc@gmail.com, nepvias@to.uftm. edu.br
} 


\section{INTRODUÇÃO}

Promoção de Saúde, na perspectiva da
Terapia Ocupacional (TO), se constrói a
partir do envolvimento dos sujeitos em ocupações significativas nos distintos contextos nos quais estão inseridos, tais como casa, escola, trabalho e comunidade. Essas ocupações são consideradas centrais para a identidade e para o senso de competência da pessoa e podem ser afetadas por diferentes motivos (AOTA, 2008).

As discussões e ações atuais da TO, especificamente em relação aos determinantes e condicionantes sociais do desempenho ocupacional, têm apontado para a necessidade do equacionamento da iniquidade e pobreza. Essas iniquidades, provenientes de processos de marginalização social, são abordadas em termos das oportunidades que as pessoas e/ou grupos têm para se envolverem em ocupações que lhe sejam significativas, caracterizando cenários de justiça ou injustiça ocupacional (POLLARD et al., 2009).

Neste sentido, as circunstâncias em que as pessoas não possuem a oportunidade de se envolver em ocupações significativas caracterizam a situação de injustiça ocupacional e justificam a adoção de estratégias de empoderamento de sujeitos e coletividades (AOTA, 2008).

Sícoli e Nascimento (2003) entendem o empoderamento como um processo que capacita as pessoas e a comunidade para que assumam um maior controle sobre fatores pessoais, sociais, econômicos e ambientais que influenciam sua saúde, podendo ser compreendido, de acordo com Carvalho (2004), de forma individual ou coletiva .

O empoderamento individual se caracteriza por estratégias que buscam a promoção da independência e autoconfiança através do fortalecimento da auto-estima, capacidade de adaptação ao contexto no qual a pessoa se insere e pelo desenvolvimento de mecanismos de autoajuda e de solidariedade, que se refletem na manifestação de comportamentos saudáveis e produtivos e aumento da percepção de bem-estar e auto-realização (CARVALHO, 2004; FISCHER; HOTCHKISS; 2008).

Já empoderamento comunitário pode ser utilizado como estratégia de enfrentamento da desigualdade na distribuição de recursos sociais e requer esforços macro e microssociais. Este processo pressupõe a redistribuição de poder, em distintas esferas da vida, e requer, primeiramente, empoderamento individual para que então ocorra a mobilização dos sujeitos, de forma coletiva, para a conquista de recursos que os permitam ter maior controle sobre suas vidas (CARVALHO, 2004).

Para a promoção do empoderamento, a TO pode se fundamentar no Modelo de Empoderamento Ocupacional (MEO), proposto em 2008 por Fischer e Hotchkiss. Inicialmente, o MEO ressalta que as influências negativas do ambiente que as pessoas estão inseridas podem resultar em um processo de desempoderamento através da ocorrência de privação ocupacional.

Entre essas influências, destaca-se a situação de vulnerabilidade social. De acordo com Castel (2005) a existência social se configura na interação de dois eixos demarcados pela inserção dos sujeitos e grupos no trabalho e nas redes sociais de suporte, que configura quatro zonas de existência social: integração, vulnerabilidade, assistência e desfiliação.

A zona de vulnerabilidade caracteriza-se por uma existência social marcada pela inserção precária no mundo do trabalho e pela fragilidade das relações sociais que se configuram como fonte de suporte (CASTEL, 2005). A vulnerabilidade, que tem origem na desigualdade social, marca o cotidiano de milhares de famílias brasileiras que vivenciam situações de uso de drogas, violência, desemprego, entre outras, que, aliadas a condições de miséria e pobreza extremas, podem limitar o potencial da família de garantirem a sobrevivência e proteção de suas crianças e adolescentes (GONTIJO; MEDEIROS, 2009; LOPES, 2006).

Nestas situações de violação dos direitos das crianças e adolescentes, são preconizadas pelo Estatuto da Criança e do Adolescente (ECA) a adoção das medidas de proteção, sendo o acolhimento institucional (abrigamento), uma das opções, utilizado em situações excepcionais (BRASIL, 1990).

Considerando estes aspectos acredita-se que a trajetória de vida de adolescentes abrigadas, marcadas pela vivência das situações de vulnerabilidade social, pode influenciar as oportunidades que estas tiveram e têm de se envolver em ocupações que sejam significativas e importantes para o seu desenvolvimento, podendo caracterizar quadros de privação e injustiça ocupacional.

Neste sentido, neste artigo objetivamos descrever e analisar o desempenho ocupacional de adolescentes abrigadas, antes e durante o acolhimento institucional. Esperamos que as nossas discussões possam subsidiar a elaboração de estratégias de empoderamento em conjunto com esta população em seus contextos reais de vida.

\section{PERCURSO METODOLÓGICO}

Esse artigo foi elaborado a partir de um recorte do 
projeto de pesquisa intitulado "A utilização do Modelo de Empoderamento Ocupacional na intervenção com adolescentes abrigadas: um estudo de caso", aprovado pelo Comitê de Ética em Pesquisa (CEP) da UFTM, sob o parecer número 1441 em 27/11/2010, cujo objetivo é descrever e analisar as possibilidades de utilização do modelo do empoderamento ocupacional junto a adolescentes com experiência de abrigamento.

Neste momento são apresentados e discutidos os resultados referentes à primeira etapa da pesquisa, cujos dados foram coletados através de entrevistas semiestruturadas e observação participante. As entrevistas gravadas e transcritas e as anotações em diário de campo, provenientes da observação, foram analisadas através de uma adaptação da técnica de Análise de Conteúdo proposta por Gomes (2007).

Os dados foram coletados em uma instituição de abrigamento de crianças e adolescentes do sexo feminino localizada em uma cidade do interior de Minas Gerais, no período de dezembro a abril de 2009. Foram convidadas a participar do estudo adolescentes com idade entre 12 e 18 anos que estavam abrigadas, sendo que quatro delas com idade entre 16 e 17 anos aceitaram o convite. O tempo de abrigamento das adolescentes variou de 08 meses a 02 anos, sendo o motivo deste negligência familiar e violência doméstica, psicológica e física.

De uma forma geral, a análise dos dados resultou em duas categorias denominadas "Caracterização do Desempenho Ocupacional" e "Redes Sociais de Suporte e Desempenho Ocupacional".

\section{RESULTADOS E DISCUSSÃO}

Na primeira categoria de análise, "Caracterização do Desempenho Ocupacional", são discutidas as atividades realizadas pelas adolescentes, antes e durante o abrigamento, relacionadas à Educação, Brincar, Lazer, Dormir e Descansar, Atividades de Vida Diária (AVD), Atividades Instrumentais de Vida Diária (AIVD), Trabalho e Participação Social.

Em relação à educação, observou-se que todas as adolescentes relataram a frequência na escola em algum momento de suas vidas no período anterior ao abrigamento. No entanto, devido ao cenário de vulnerabilidade social vivenciado pelas famílias de origem, observam-se atrasos temporais na inserção na escola assim como interrupções nesta trajetória em virtude de entrada no mundo do trabalho ou a necessidade de cuidar de familiares, principalmente idosos ou crianças menores, caracterizando limitações ou privações no desempenho ocupacional.
"[Eu parei de estudar] Porque minha avó adoeceu e eu tive que cuidar dela. Ai a minha mãe ela foi embora com um homem ai e falou que era pra eu cuidar da minha avó" (E4)

Atualmente as adolescentes frequentam a escola e relatam a oportunidade de desenvolverem outras atividades relacionadas ao contexto, tais como curso de informática, monitoria para as crianças mais novas e aula de ginástica artística.

Através das entrevistas, foi possível perceber que as adolescentes identificam a escola como um ambiente importante para que as mesmas tenham êxito no futuro profissional. Muitas demonstraram interesse em ter profissões de nível superior, e uma delas ressaltou que gostaria de fazer um curso universitário em alguma universidade pública de outra cidade. Neste sentido, é importante destacar que o abrigo atua no sentido contrário à privação ocupacional, uma vez que, por seguir os princípios do ECA, possibilita a inserção e permanência das adolescentes neste contexto, além de ampliar as oportunidades de realização de atividades extracurriculares.

O brincar também foi alvo de caracterização neste estudo. De uma forma geral, as adolescentes relatam a presença do brincar em seu cotidiano na infância. Elas destacaram que possuíam brinquedos, principalmente bonecas e ursinhos, e que inicialmente passavam a maior parte do dia envolvidas em brincadeiras. Além disso, as adolescentes destacam que ficavam muito tempo na rua brincando de bete, queimada, rouba bandeira e bola e que possuíam amigos que compartilhavam essas brincadeiras, como vizinhos e familiares.

No entanto, as garotas apontam que em algum momento de suas vidas foram privadas do brincar principalmente devido ao envolvimento em atividades de trabalho fora e dentro de suas residências, conforme será discutido posteriormente.

"Porque [minha mãe] falava assim que eu não era mais criança e que eu tinha que trabalhar. E isso não era certo não, e eu achava muito injusto isso." (E4)

Atualmente as adolescentes destacam que não gostam de brincar como faziam enquanto crianças, mas que ainda possuem os ursinhos e bonecas e os utilizam para enfeitar seus quartos. As garotas mencionaram que ainda brincam de bete, queimada e futebol, entre outras, sendo estas realizadas em companhia das outras meninas que residem no abrigo. Além disso, ressaltaram que sempre que é possível, essas brincadeiras são realizadas fora da instituição, em um espaço comunitário próximo ao abrigo.

Neiva-Silva e Koller (2009) ressaltam que o brincar, 
CARLETO, D. G. S. et al. Promoção de Saúde. Rev. Ter. Ocup. Univ. São Paulo, v. 21, n. 1, p. 89-97, jan./abr. 2010.

independente do contexto no qual ocorre, estimula o desenvolvimento infantil. Essas autoras destacam que a rua representa um universo para a socialização infantil, pois através das brincadeiras, as crianças podem constituir redes sociais de suporte compostas por vizinhos, parentes, colegas de escola e amigos. Por outro lado, é importante apontar que, no caso das adolescentes que compuseram este estudo, a vivência do brincar, de forma intensa, no contexto da rua, pode refletir a situação de vulnerabilidade de suas famílias, uma vez que pode representar a ausência de controle parental sobre o cotidiano destas.

Em relação ao lazer, inicialmente é importante destacar que as adolescentes compreendem o sono e descanso (outra área de ocupação) como uma forma de lazer, assim como associam o lazer a participação social. Anterior ao abrigamento, as adolescentes relataram distintas atividades de lazer realizadas com familiares como passeios e brincadeiras. Uma delas realizava as atividades com uma amiga, indo para sua casa conversar e passar o tempo, além de brincar, assistir televisão e sair com sua mãe, enquanto outra gostava de ler. Contudo, quando as adolescentes tiveram que trabalhar, observa-se limitação no desempenho ocupacional relacionado ao lazer.

Atualmente as adolescentes identificam como atividades de lazer dormir, descansar, assistir televisão, ler livros, ouvir músicas e realizar passeios, como ir a clubes e peças teatrais. Algumas dessas atividades são programadas pela equipe do abrigo, a partir da solicitação das adolescentes, e para que elas ocorram, todas devem participar.

"Ah, a gente vai no clube nos feriados, vai no teatro, é só a gente falar pra tia que a gente quer ir e ai elas leva a gente" (E1)

As adolescentes apontam que anterior ao abrigamento decidiam o quê fazer, o que pode representar tanto um processo de construção de autonomia, quanto uma ausência do controle parental, conforme discutido anteriormente. Atualmente, as adolescentes manifestam o desejo de realizar atividades de lazer típicas de sua faixa etária, tais como fazer ginástica na academia, caminhar, andar de bicicleta, ir a festas, entre outras. No entanto, as garotas apontam uma limitação nestas atividades devido à impossibilidade de realizá-las individualmente, uma vez que, de acordo com os princípios da instituição, estas devem ser realizadas coletivamente.

"Ah, [eu queria ir em] qualquer tipo de festa. Sabe, eu adoro muita festa, muita gente. [Mas] se uma menina da minha sala me chama pra ir e não chama outra menina da casa, ai eu não posso ir porque eu não posso ir sozinha." (E1)
Em relação ao lazer observam-se cenários de limitação no desempenho ocupacional no período anterior ao abrigamento, em decorrência da inserção no trabalho, e atualmente em decorrência do funcionamento institucional. No entanto, é importante pontuar que o abrigo também proporcionou para as adolescentes uma ampliação do leque de atividades de lazer, principalmente com a introdução de atividades culturais. Estes aspectos, conforme discutido por Queiroz e Souza (2009), apontam a influência do contexto social e cultural no desempenho de atividades de lazer.

Caracteriza-se também, nesta categoria, o desempenho das adolescentes nas Atividades de Vida Diária (AVD) e nas Atividades Instrumentais de Vida Diária (AIVD) (AOTA, 2008). As adolescentes relataram que aprenderam a realizar algumas AVDs de forma precoce, uma vez que durante sua infância, não possuíam ajuda para a execução de atividades de autocuidado (tomar banho) e preparo de refeições, tendo de realizá-las de forma independente em idades onde isto não é esperado, fato que caracteriza a falta de suporte para o desempenho ocupacional. Além disso, as adolescentes referiram a realização de atividades domésticas e de cuidado com outras pessoas, sendo que estas serão discutidas posteriormente sob a perspectiva de trabalho infantil.

"Minha mãe não fazia nada disso por mim, eu tive que aprender [a tomar banho e a preparar refeições] sozinha." (E4)

Atualmente as adolescentes realizam atividades de manutenção do abrigo e de objetos pessoais, de acordo com a rotina que é estabelecida na instituição, além daquelas relacionadas ao autocuidado (cuidar dos cabelos e fazer unha, por exemplo).

Quando se discute o desempenho de atividades de trabalho, a vulnerabilidade social vivenciada pelas adolescentes se manifesta de forma intensa. As adolescentes, exceto uma delas, relataram a vivência de trabalho remunerado relacionado às atividades domésticas fora de suas residências, tais como arrumar casa, limpar chão, lavar vasilhas, entre outras, antes de 16 anos, idade legalmente aceita para a realização desse tipo de atividade (BRASIL, 1990). Os principais motivos alegados para o trabalho foram a falta de dinheiro e a necessidade de acompanhar um adulto nessa tarefa.

"Lá onde eu trabalhava eu recebia 180, e no outro lugar era por dia. Então cada coisa que eu fazia era cinco reais. Se eu limpasse o chão, o balcão e lavasse a louça era cinco. A única coisa que era dez era a assadeira, porque era muito dificil. E eu usava um produto químico que comeu minha mão tudo."( E1)

Atualmente as adolescentes que trabalham o fazem na gráfica do colégio particular responsável pela 
manutenção do abrigo. Elas ou estão protegidas pela lei de menor aprendiz (as que possuem menos de 16 anos) ou já possuem carteira assinada. Essa oportunidade de trabalhar que a instituição oferece às adolescentes é diferente da oportunidade que elas tiveram de trabalhar antes de morarem no abrigo, caracterizadas como exploração da mão de obra infantil, pois naquela ocasião elas não tinham direitos trabalhistas assegurados e tiveram que trabalhar precocemente, interrompendo atividades esperadas para a sua faixa etária, como escola, brincar e lazer.

Em suas residências, as adolescentes também eram as responsáveis pela realização de atividades domésticas, principalmente porque não havia um adulto que as desempenhassem. As adolescentes também destacaram, em sua maioria, que tiveram que cuidar de irmãos mais novos, principalmente pela ausência da figura materna para se responsabilizar por tal atividade. Além disso, uma entrevistada ressaltou que teve que cuidar de sua avó que adoeceu, pois sua mãe não assumiu essa tarefa.

"É, eu cuidava da minha casa. Minha mãe só ficava na rua. Ela chegava tava janta pronta, a casa toda arrumada, as roupa dela tudo limpinha." (E2)

"Por eles [meus irmãos]? [Eu fazia] Tudo! Eles já foram... Eu fazia comida, dava banho, quando era nenê eu trocava a frauda."(E4)

$\mathrm{Na}$ instituição, atualmente, as adolescentes também devem realizar atividades relacionadas aos cuidados domésticos, como lavar suas roupas e arrumar a casa. Contudo, o propósito da realização desse tipo de atividade é diferente, pois essas são necessárias para a estruturação do cotidiano das adolescentes, sendo estas adequadas a faixa etária e realizadas de forma equilibrada com outras ocupações.

"Cada dia a gente tem que olhar no quadro pra ver qual obrigação a gente tem que cumprir, que nem, tem de segunda a domingo, aí a gente lava o banheiro, limpa o corredor." (E1)

Finalmente, a última área de ocupação caracterizada refere-se à Participação Social. Antes de morarem no abrigo, as adolescentes relataram a realização de atividades de participação social, vinculadas ao lazer, tais como ir à festas com amigos e passear com a família. As adolescentes destacam que ir pescar, tomar sorvete, comer pizza e ir à casa de parentes foram as principais atividades que realizaram com seus familiares, principalmente tios e primos. No entanto, duas adolescentes relataram que não realizavam atividades com suas famílias.

Contudo, elas destacam algumas situações que limitaram o envolvimento nessas atividades, como o padrasto de uma delas impedi-la de se relacionar com seus irmãos e com sua mãe e também pela ausência da mãe biológica de algumas durante a realização dessas atividades.

"Ele [meu padrasto] não deixava vestir curto, eu me arrumar, não deixava em ir em festa, nem conversar com nenhum menino mesmo que fosse colega de escola." (E3)

Atualmente as adolescentes não realizam atividades com sua família, exceto quando recebem visitas esporádicas no abrigo. As adolescentes têm a oportunidade de realizar atividades de participação social, no entanto destacam as limitações impostas pela institucionalização, relatando que gostariam de sair com suas amigas de escola para o shopping ou então receber visitas dessas pessoas, mas nem sempre podem realizá-las.

"Igual, a gente tem trabalho na casa do colega pra fazer, mas a gente não pode sair daqui. Eles têm que vir aqui, mas tem vez que nem eles podem vir." (E2)

Uma das adolescentes relatou que gostaria de ir à igreja, mas que não pode porque ela é a única evangélica da instituição, e se abrirem uma exceção para que ela vá à igreja, essa exceção terá que ser aberta para todas as adolescentes.

"Eu ia direto na universal. Mas daqui agora eu não posso ir. Porque também se eu quiser ir e abrirem uma exceção pra mim, vão ter que abrir exceção pra outras meninas aqui." (E3)

$\mathrm{Na}$ segunda categoria de análise, denominada "Redes Sociais de Suporte e Desempenho Ocupacional", destacase a relação das redes sociais de suporte das adolescentes com o desempenho ocupacional. De uma forma geral, as adolescentes relatam que suas redes sociais de suporte foram e/ou são constituídas, principalmente, por família, professoras, projetos sociais, amigos, namorados e pelo abrigo. Além disso, destacam como o suporte social influencia em seu envolvimento em atividades em distintas áreas de ocupação.

As redes sociais de suporte freqüentemente estão associadas a aspectos objetivos (amigos, relações interpessoais, família, igrejas, associações, ONGs) e subjetivos (satisfação da pessoa com sua vida e com as relações interpessoais que mantém) e podem ser definidas como a existência de pessoas e grupos sociais que apóiam as pessoas frente aos acontecimentos de sua vida e que fornecem assistência e ajuda aos que necessitam (RIBEIRO, 1999). Segundo o referencial de Castel, as redes sociais de suporte são um dos fatores que delimitam as zonas de existência social, sendo que seu fortalecimento ou enfraquecimento caracterizam as formas de vida dos sujeitos (CASTEL, 2005; GONTIJO; MEDEIROS, 2009; LOPES, 2006).

Em relação à família, as adolescentes destacam 
CARLETO, D. G. S. et al. Promoção de Saúde. Rev. Ter. Ocup. Univ. São Paulo, v. 21, n. 1, p. 89-97, jan./abr. 2010.

ausência de pais e mães durante a realização de atividades de participação social e AVDs e negligência por parte da mãe biológica.

"É, nunca tive minha mãe pra me ajudar em alguma coisa. Eu morava com a minha mãe, mas eu ia pra casa da minha tia. Eu tomava banho, me arrumava lá. Aí de vez em quando eu pedia pra ela arrumar o meu cabelo, ai ela me ajudava." (E2)

As adolescentes também relatam situações de abandono. Uma delas foi abandonada em um terreno baldio quando tinha dois meses de idade, e em determinado momento de sua vida, sua mãe de criação a devolveu para a mãe biológica, caracterizando uma nova situação de abandono. Outra adolescente também relatou que foi abandonada pela mãe, que a deixou na casa de uma tia e não voltou para buscá-la.

"Não, ela [minha mãe] me abandonou no meio do mato mesmo. Porque lá perto de casa, o bairro que eu moro só tem quatro ruas e lá é cheio de mangueira, ai nessa época ela me deixou lá." (E1)

As adolescentes ressaltaram que suas mães biológicas possuíam problemas com drogas ou envolvimento sentimental com diversos homens. A maioria delas se refere à mãe biológica pelo nome, não as chamando de mãe. Somente uma das adolescentes se referiu à figura materna como fonte de suporte social, sendo a ausência da figura paterna observada no discurso de todas as adolescentes.

"E ai ela [minha mãe] mexe com droga, essas coisas, então ela tirava as coisas de casa, sabe, pra sustentar o vício. E por isso eu tive que sair da escola e ir trabalhar." (E1)

Neste aspecto, é importante ressaltar que a negligência familiar, associada à vulnerabilidade social das famílias, foi constante nesse estudo. Para Martins e Jorge (2009) a negligência familiar tem repercussão biopsicossocial, pois interfere diretamente nos âmbitos físico, psicológico, cognitivo, emocional e comportamental, e pode ser evidenciada, entre outros aspectos, pela falta de suporte emocional e afetivo à criança.

Gomes e Pereira (2005) destacam que a dinâmica e a estrutura familiar têm sido modificadas nos últimos anos, principalmente pela diversidade das relações que ocorrem entre as pessoas que constituem uma família. As autoras ressaltam que atualmente a família vem sendo constituída por pessoas que mantêm relações interpessoais de afeto, proteção e solidariedade, e não somente por pessoas com laços de sangue. Essa nova caracterização de família pôde ser percebida nesse estudo, pois as adolescentes se referiram a outros parentes e a amigos como uma nova configuração de família e como fonte de suporte social.
"Eu... Eu tinha boneca, eu tenho lá na casa da minha tia guardada no guarda-roupa. Porque minha tia tudo que ela comprava pra minha prima, ela comprava pra mim. Eles foram mais minha mãe do que ela mesmo." (E2)

Foi possível constatar que o contexto familiar das adolescentes, apesar de esporadicamente ter promovido condições para que as mesmas se envolvessem em ocupações significativas, muitas vezes se configurou como um ambiente desempoderador, por proporcionar muitas situações de privação ocupacional como parar de brincar, de estudar ou de realizar atividades de lazer.

Outra fonte de suporte social identificada pelas adolescentes foram as professoras, que atuaram em momentos nos quais estas tiveram problemas com suas famílias, principalmente com mães biológicas. Elas relatam que nas situações de trabalho infantil, discutidas anteriormente, as professoras se dispuseram a ajudá-las, procurando auxílio de instituições como o Conselho Tutelar ou o abrigo.

"Elas me ajudaram muito, chamaram o conselho pra minha mãe porque ela não me deixava brincar e queria que eu trabalhasse. (E4)"

Percebe-se como as professoras atuaram como fator importante de fortalecimento da inserção relacional, enfrentando o agravamento de situações de vulnerabilidade vivenciado pelas adolescentes. O suporte social oferecido por professores é discutido por Ruiz (2003), que ressalta que a educação é um processo que perpassa por conteúdos, métodos e técnicas e atinge um patamar no qual os alunos recorrem aos professores na busca de soluções para seus problemas sociais.

Outra fonte de suporte social percebida pelas adolescentes se refere aos projetos sociais, nos quais se destaca a possibilidade de aprendizado de distintas atividades, como tricô, bordado, pintura, música e teatro. Elas ressaltam que estiveram envolvidas com projetos sociais antes do abrigamento e demonstram entusiasmo ao relatar suas experiências nos projetos. Esses projetos ocorreram a partir de iniciativas de Organizações Não Governamentais (ONGs) e possibilitaram que as adolescentes se envolvessem em ocupações positivas e significativas, de acordo com o relato das mesmas.

"Projeto Beira da Estrada. [Eu fazia] Era curso de bordado, pintura, moldura, confecção de roupas com coisas da natureza." (E3)

O envolvimento das adolescentes em projetos sociais possibilitou o fortalecimento da inserção relacional. Castro et al. (2001) destacam que a partir de projetos sociais, os adolescentes podem desenvolver, principalmente, protagonismo juvenil, processo que possibilita que o jovem 
se aproprie da condição de sujeito de suas atividades, além de atuarem no desenvolvimento de auto-estima, pertencimento a grupos, identidade, conscientização identitária e cidadania.

Considerando os amigos, antes do abrigamento, as adolescentes declararam que estes eram representados principalmente por pessoas que moravam perto de suas casas e também por colegas da escola, com os quais brincavam e realizavam atividades de lazer, como ir à sorveteria. Uma adolescente ressaltou que uma amiga serviu como importante fonte de suporte social:

"Nessa época que eu tava morando com ela, eu tenho uma amiga, e eu morro de vontade de fazer contato com ela, sabe, porque ela me deu muito conselho, sabe? Que era pra mim nunca desistir dos meus sonhos, pra mim sempre correr atrás. Que não era pra mim nunca deixar meus problemas ser maior que eu." (E1)

Atualmente as adolescentes declararam que os principais amigos são os da escola ou as próprias meninas que moram no abrigo. Uma adolescente disse que seus principais amigos são colegas de trabalho.

"Minhas amigas são as meninas aqui da casa, colega de rua eu não tenho mais não." (E4)

Especificamente em relação aos amigos enquanto suporte social, Gontijo e Medeiros (2009) ressaltam que as amizades são fatores positivos para adolescentes em situação de vulnerabilidade social, uma vez que proporcionam ajuda mútua, proteção e diversão.

Com relação ao namoro, antes de morarem no abrigo, a maioria das adolescentes relatou ter tido namorados, todos também adolescentes. Uma delas declarou que manteve união consensual e ressaltou que um dos motivos para isso foi não ter um local para morar.

"Aí eu tive um namorado. Aí eu fui morar com ele. Eu tinha 14 [anos]." (E1)

Atualmente as adolescentes destacaram que não possuem namorados. Contudo, dados obtidos através de observação se contrapõem com esse discurso, pois elas relatam namorar na escola e destacam que, se houver um consenso entre elas e a equipe do abrigo sobre as normas da instituição, podem namorar no abrigo.

Finalmente, em relação ao abrigo, as adolescentes relatam que as regras da instituição interferem em seu desempenho ocupacional, principalmente para a realização de atividades com amigos, como ir ao shopping, cinema e também as de lazer, evidenciadas pela vontade de fazer exercícios físicos e de ir às festas.

Por outro lado, o abrigo possibilita que as adolescentes se envolvam em atividades que não realizariam se ainda estivessem com suas famílias de origem, principalmente atividades culturais e educacionais, além de impedir o envolvimento em ocupações não adequadas para a faixa etária, principalmente as situações de exploração do trabalho infanto-juvenil.

"A gente sai dia de domingo, dia de feriado. A gente vai no clube, já foi no teatro. (E1)

Neste sentido, o abrigo se caracteriza enquanto fonte de suporte social que possibilita a transição das adolescentes da zona de vulnerabilidade para a de assistência. Na zona de assistência, de acordo com Castel, estão os sujeitos e grupos sociais que não podem se inserir no mundo do trabalho (por idade ou nível de habilidade) e que são providos de forte suporte assistencial (neste caso, o acolhimento institucional) (CASTEL, 2005). Neste contexto, de maior proteção e acesso a direitos básicos, podem ser desenvolvidas estratégias de empoderamento que possibilitem que estas adolescentes caminhem rumo à zona de integração, caracterizada por inserção sólida no mundo do trabalho e forte suporte social.

\section{CONSIDERAÇÕES FINAIS}

Este estudo possibilitou a compreensão da complexidade de fatores que caracterizam o desempenho ocupacional de sujeitos que vivenciam a vulnerabilidade social. Situações de privação ocupacional que se mesclam com o desempenho de ocupações não esperadas e desejadas na infância e adolescência, se articulam principalmente com o suporte social limitado pelas famílias, também aqui compreendidas enquanto vítimas da desigualdade e injustiça social, caracterizando o cenário de injustiça ocupacional.

Neste sentido, é importante ressaltar a impossibilidade de utilização de análises simplistas do desempenho ocupacional, que caracterizem um determinado contexto como empoderador ou desempoderador, uma vez que, conforme apontado pelas adolescentes, um mesmo ambiente pode apresentar fatores que ampliam ou limitam o desempenho ocupacional.

Um ponto que merece destaque se refere ao desafio enfrentado pelas instituições de acolhimento no que se refere à promoção da autonomia das adolescentes. Este desafio se relaciona, entre outros aspectos, à capacidade de promover a elaboração de projetos de empoderamento e envolvimento em atividades significativas de forma individualizada no contexto da coletividade. É neste cenário que o terapeuta ocupacional pode contribuir significativamente, sendo a utilização do MEO uma das possibilidades para as intervenções.

Especificamente em relação ao MEO, foi possível vislumbrar a sua utilização junto a esta população, enquanto 
CARLETO, D. G. S. et al. Promoção de Saúde. Rev. Ter. Ocup. Univ. São Paulo, v. 21, n. 1, p. 89-97, jan./abr. 2010.

uma estratégia de empoderamento individual direcionada para o fortalecimento da auto-estima e da resiliência. Acredita-se que, conforme aponta Fischer e Hotchkiss (2008), o empoderamento ocupacional poderá estimular processos de tomada de decisões e controle sobre as próprias vidas por parte das adolescentes, resultando em melhora em seu desempenho ocupacional.

No entanto, acredita-se que aliadas às ações direcionadas para a promoção dos processos de tomadas de decisões e controle de vida por parte das adolescentes, são necessárias ações que atuem diretamente no ambiente desempoderador vivenciado por estas, no sentido de fortalecimento das redes sociais de suporte. Neste sentido, aponta-se a necessidade de ações da TO diretamente com as famílias de origem ou substitutas, assim como com a escola e instituição de acolhimento, que se revertam em mudanças no contexto de vida das adolescentes, lhes permitindo oportunidades e condições necessárias para o seu empoderamento.

Ainda em relação ao MEO é importante pontuar que até o momento não foram desenvolvidos instrumentos padronizados e validados que possibilitem caracterizar o ambiente desempoderador. O desenvolvimento destes instrumentos assim como a avaliação da efetividade de sua utilização junto a esta população no contexto brasileiro se caracteriza como novas possibilidades de pesquisa neste campo.

Finalmente, esperamos que as discussões aqui apresentadas possam subsidiar a elaboração de ações da TO com adolescentes em situação de vulnerabilidade social que se revertam em superação das situações de injustiça e privação ocupacionais e melhorias nas suas percepções de saúde e bem estar.

CARLETO, D. G. S.; ALVES, H. C.; GONTIJO, D. T. Health Promotion, Occupational Performance and Social Vulnerability: subsidies for Occupational Therapy intervention with adolescents sheltered. Rev. Ter. Ocup. Univ. São Paulo, v. 21, n. 1, p. 89-97, jan./abr. 2010.

\begin{abstract}
The health promotion in the perspective of the occupational therapy is constructed from the involvement of the subjects in significant occupations. Circumstances in which people don't' have the opportunity of engaging itself characterize the situation of occupational injustice, justifying the adoption of strategies of empowerment that might be based upon the model of occupational empowerment. It is outlined among these circumstances; the situations of social vulnerabilities faced by adolescents that were institutionally supported. This article aims to describe and analyze the occupational development of adolescents, before and during the institutional support. The data were collected in a female children and adolescent support institution by the means of a semi-structured interview and participative observation, and analyzed from an adapted content analysis technique. Two analyses categories were elaborated in which they are discussed the activities accomplished by adolescents before and during the support related to the distinctive areas of occupation, besides of the relation of social webs of support of the adolescents with occupational performance. Generally saying, it was possible to realize the complexity of the factors that characterize the occupational development adolescents who face the social vulnerability, being necessary empowerment actions, with positive repercussions in the perceptions of the health conditions, that guided interventions to the adolescents themselves, as well as the actions of strengthening the social support net.
\end{abstract}

KEY WORDS: Occupational therapy. Social vulnerability. Adolescent. Health promotion.

\title{
REFERÊNCIAS
}

AOTA. Occupational Therapy Practice Framework: Domain \& Process. 2a ed. Am. J. Occup. Ther., v. 62, n. 6, p. 625-683, 2008.

BRASIL. Estatuto da criança e do adolescente. Lei n. 8.069, de 13 de julho de 1990, Lei n. 8.242, de 12 de outubro de 1991. - 3. ed. - Brasília: Câmara dos Deputados, Coordenação de
Publicações, 1990.

CARVALHO, S. R. Os múltiplos sentidos da categoria "empowerment" no projeto de Promoção à Saúde. Cad. Saúde Pública, v. 20, n. 4, p. 1088-1095, 2004.

CARVALHO, S. R.; GASTALDO, D. Promoção à saúde e 
empoderamento: uma reflexão a partir das perspectivas críticosocial pós-estruturalista. Ciênc. Saúde Coletiva, v. 13, supl. 2, p. 2029-2040, 2008.

CASTEL, R. As metamorfoses da questão social: uma crônica do salário. 5a ed. Petrópolis, 2005.

CASTRO, M. G.; ABRAMOVAI, M.; RUA, M. G.; ANDRADE, E. R. Cultivando vida, desarmando violência: experiências em educação, cultura, lazer, esporte e cidadania com jovens em situação de pobreza. Brasília: UNESCO, Brasil Telecom, Fundação Kellogg, Banco Interamericano de Desenvolvimento, 2001.

FISCHER, G. S.; HOTCHKISS, A. Um modelo de empoderamento ocupacional para populações marginalizadas em ambientes comunitários. Occup. Ther. Health Care, v. 22, n. 1, 2008.

GOMES, M. A.; PEREIRA, M. L. D. Família em situação de vulnerabilidade social: uma questão de políticas públicas. Ciên. Saúde Coletiva, v. 10, n. 2, p. 357-363, 2005.

GOMES, R. Análise e interpretação de dados de pesquisa qualitativa. In: MINAYO, M. C. S.; DESLANDES, S. F.; GOMES, R. Pesquisa social: teoria, método e criatividade. 25a ed. Petrópolis: Vozes, 2007. p.79-108.

GONTIJO, D. T.; MEDEIROS, M. Crianças e adolescentes em situação de rua: contribuições para a compreensão dos processos de vulnerabilidade e desfiliação social. Ciên. Saúde Coletiva, v. 14, n. 2, p. 467-475, 2009.

LOPES, R. E. Terapia ocupacional social e a infância e a juventude pobres: experiências do Núcleo UFSCAR do Projeto Metuia. $\mathrm{Cad}$. Ter. Ocup. UFSCar, v. 14, n. 1, 2006.

MARTINS, C. B. G.; JORGE, M. H. P. M. Negligência e abandono de crianças e adolescentes: análise dos casos notificados em município do Paraná, Brasil. Pediatria (São Paulo), v. 31, n. 3, p. 198-197, 2009.

NEIVA-SILVA, L.; KOLLER, S. H. A rua como contexto de desenvolvimento. In: PINTO, T. O.; LOPES, M. F. Brincadeira no espaço da rua e a demarcação dos gêneros na infância. Rev. Latinoam. Cienc. Soc. Niñez Juv, v. 7, n. 2, p. 861-885, 2009.

QUEIROZ, M. N. G.; SOUZA, L. K. Atividades de Lazer em Jovens e Adultos: Um Estudo Descritivo. Licere, Belo Horizonte, v. 12, n. 3, 2009.

POLLARD, N.; SAKELLARIOU, D.; KRONEMBERG, F. $A$ political practice of occupational therapy. Filadélfia: Elsevier Churcill Livingstone, 2009.

RIBEIRO, J. L. P. Escala de satisfação com o suporte social (ESSS). Análise Psicol., v. 3, n. 17, p. 547-558, 1999.

RUIZ, M. J. F. O papel social do professor: uma contribuição da filosofia da educação e do pensamento freireano à formação do professor. Rev. Iberoamer. Educación, n. 33, p. 55-70, 2003.

SICOLI, J. L.; NASCIMENTO, P. R. Promoção de saúde: concepções, princípios e operacionalização. Interface (Botucatu), v. 7 , n. 12 , p. $101-122,2003$.

\section{Contribuições dos autores:}

Daniel Gustavo de Sousa Carleto: elaborou o projeto de pesquisa, coletou e analisou os dados e redigiu o manuscrito.

Heliana Castro Alves: realizou a revisão do manuscrito.

Daniela Tavares Gontijo: orientou o desenvolvimento do projeto de pesquisa, (incluindo planejamento, coleta e análise de dados) e a redação do artigo, assim como realizou a revisão do manuscrito. 